Aim Cognitive impairment is seen in patients with paediatric multiple sclerosis in more than $30 \%$ of cases. Altered functions with variable frequency are: attention, language (receptive, verbal fluency, naming), visual-spatial and motor functions, spatial memory, executive functions and abstract reasoning. The aim of this study is to determinate the cognitive functions disorders in children with multiple sclerosis.

Methods A total of 21 individuals with paediatric MS (19 girls, 2 boys), ranging from $10-17$ years of age $(S D=14.90 \pm 186)$ completed initial and follow-up neuropsychological testing at yearly interval. All the patients were given WISC-R, Raven's Standard Progressive Matrices, Wisconsin Card Sorting, Stroop Test, Line Orientation Test and Verbal Fluency

Results $55 \%$ of the patients had Interferon therapy, First attack age was $12.92 \pm 2.36$, total number of attacks was $2.68 \pm 2.19$. IQ assessment was as follows: $19.1 \%(n=4)$ borderline, $47.6 \%$ $(\mathrm{n}=10)$ average, $33.4 \%(\mathrm{n}=7)$ high average. After interferon therapy; patients showed increased reponse time with less mistakes in Stroop test $(\mathrm{p}<0.05)$, there was an increase of vocabulary scores in Verbal Fluency Test, being is still behind the scores of normal children. Visual-spatial perception impairments became evident right after the attacks. Symptoms of depression have been found in the $25 \%$ of the patients. There is a correlation ( $r$ : 0.82) between tnumber of attacks, cognitive loss, and depression.

Conclusion Cognitive impairment has a negative impact on patient's life limiting social, academic activities. Early treatment with disease-modifying drugs seems to be advisable in order to prevent or delay the development of cognitive impairment.

\section{PO-0837 EFFICACY AND SIDE EFFECTS OF AZATHIOPRINE AND ASPIRIN IN CHILDHOOD PRIMARY ARTERIAL STROKE}

${ }^{1} \mathrm{G}$ Hasan, ${ }^{2}$ A Alhaboob. ${ }^{1}$ Pediatrics, Assiut University Hospital, Assiut, Egypt; ${ }^{2}$ Pediatrics, King Khalid University Hospital and College of Medicine, Riyadh, Saudi Arabia

10.1136/archdischild-2014-307384.1468

Objectives To describe cohort of children with childhood Primary Angiitis of Central Nervous System (cPACNS); report their neurological outcome; evaluate efficacy and safety of used therapies.

Study design Observational Cohort Study.

Settings Tertiary Care Children Hospital at Pakistan.

Methods The study included patients presented with acute ischaemic strokes (AIS) to Department of Neurosciences at Children's Hospital, Lahor, Pakistan over 2 years (January 2009-December 2010). Their age $\leq 16$ years; admitted within 14 days of symptoms onset and they were subjected to through history taking; complete physical examination; laboratory and neuroimaging evaluation. They received pulses of intravenous Steroids and/or Immunoglobulin and Anticoagulant for 4 week followed by maintenance therapy with Azathioprine and low dose Aspirin for 24 months.

Results Sixty Eight patients were included, 42 (62.76\%) boys and $26(38.23 \%)$ girls, mean age was $8.5 \pm 3.5$ years. Presenting symptoms and signs were; fever (20\%), headache (64\%), disturbed consciousness (30\%), seizures 55\%, hemiparesis $(60 \%)$, and motor deficit (70\%). Neuroimaging studies revealed: ischaemic strokes in $50(73.5 \%)$, haemorrhagic strokes in $10(14.7 \%)$ and ischaemic-haemorrhagic lesions in 8 (11.8\%). Male sex, deep coma and raised intracranial pressure were poor prognostic signs. Outcome revealed; 12 deaths (17.64\%), 11 normal
(16.17\%), 14 (20.59\%) had minor disabilities, 11 (16.17\%) with moderate disabilities and 20 (29.41\%) had severe disabilities.

Conclusions Characteristic features of cPACNS on presentation may predict progression and outcome; identify high-risk patients; and guide selection of patients for immunosuppressive therapy. Further studies are required to substantiate our findings regarding immunosuppressive therapy for such patients.

\section{PO-0838 WITHDRAWN}

\section{P0-0839 CAPNOGRAPHY IN PATIENTS WITH SEVERE NEUROLOGICAL IMPAIRMENT}

R Jacob, A Nelkenbaum, R Brik. Pediatrics B, Rambam Health Care Campus, Haifa, Israel

10.1136/archdischild-2014-307384.1469

Background Respiratory disease is a common reason for hospitalisation and mortality in persons with severe intellectual and developmental disability. Assessment of acute respiratory decompensation and differentiating it from chronic pathology is a frequently encountered challenge. Partial pressure of $\mathrm{CO} 2$ is commonly used as an aid in this setting.

Aim To evaluate baseline end tidal CO2 (EtCO2) levels using non-invasive side stream capnometry and to identify factors correlated with higher capnometry readings in this patient population.

Methods This was a prospective, case controlled, cross sectional study to assess differences of baseline $\mathrm{EtCO} 2$ values between neurologically impaired patients and healthy individuals. Patient's demographic and clinical data were recorded. Variables correlating with higher EtCO2 readings and those that may predict clinically meaningful difference among neurologically impaired patients were evaluated.

Results Seventy eight patients and 53 healthy individuals were included. The mean $( \pm \mathrm{SD})$ EtCO2 values were higher for neurologically impaired patients as compared to healthy individuals $(39.14 \pm 3.59$ and $37.11 \pm 1.88 \mathrm{mmHg}$ respectively; $\mathrm{p}<$ $0.0001)$, and highest among patients using antipsychotic medications $(41.53 \pm 5.257 \mathrm{mmHg})$. Kyphoscoliosis and the use of antipsychotic drugs were the major factors to increase $\mathrm{EtCO}^{2}$ levels.

Conclusion Knowing the patient's baseline EtCO2 value, as well as baseline oximetry, could guide treatment decisions, when assessing the patient's oxygenation and ventilation during acute respiratory illness. Future research can shed light on the utility of capnometry and clinical implications of higher baseline $\mathrm{EtCO}^{2}$ values among neurologically impaired patients.

\section{PO-0840 PARENT-REPORTED PAIN IN NON-VERBAL CHILDREN AND ADOLESCENTS WITH CEREBRAL PALSY}

${ }^{1} \mathrm{~S}$ Jayanath, ${ }^{1} \mathrm{LC}$ Ong, ${ }^{1} \mathrm{MJ}$ Marret, ${ }^{2} \mathrm{~A}$ Ahmad Fauzi. 'Department of Paediatrics, University of Malaya, Kuala Lumpur, Malaysia; ${ }^{2}$ Department of Rehabilitation Medicine, University of Malaya, Kuala Lumpur, Malaysia

\subsection{6/archdischild-2014-307384.1470}

Background and aims This study aimed to (i) determine the prevalence of parent-reported pain among non-verbal children with cerebral palsy (CP), (ii) determine the frequency and 
intensity of pain and (iii) explore associations with medical, parental and socioeconomic factors.

Methods The study was cross-sectional. Participants were parents of non-verbal CP outpatients at University Malaya Medical Centre, Kuala Lumpur and two centres in the surrounding area. Patients were aged 2-19 years. Written informed consent was obtained. The Caregiver Priorities and Child Health Index of Life with Disabilities (CPCHILDC) Questionnaire and a separate proforma were utilised for assessment of frequency and intensity of pain during the preceeding 4 weeks. Parental psychosocial well being was assessed via the Depression, Anxiety and Stress Scale (DASS-21) and the Multidimensional Scale of Perceived Social Support (MSPSS).

Results The response rate was 94\%, including 104 children (54 boys, 50 girls). The majority (51\%) had GMFCS level V and $65 \%$ had spastic quadriplegia. Reported pain was $65 \%$. The most frequent and intense pain was during physiotherapy. Nineteen $(18 \%)$ reported that their children experienced pain $>1$ time per day and $10 \%$ reported daily pain. Severe pain was reported by $17 \%$. There were no significant factors associated with frequency of pain. Older children $(p<0.05)$, those with spastic quadriplegia $(\mathrm{p}<0.05)$ and poorer quality of life $(\mathrm{p}<$ 0.05 ) had more intense pain. GMFCS level, gender, co-morbidities, parental psychosocial scores, parental education and income were not significant modifying factors of intensity of pain.

Conclusion Recognition of pain in non-verbal CP patients is crucial for holistic management.

\section{PO-0841 WITHDRAWN}

\section{PO-0842 OPTIMAL EMOTIONAL DEVELOPMENT IN YOUNG CHILDREN: THE ROLE OF PARENTS AND PAEDIATRICIANS}

SU Johnson. Discipline of Paediatrics and Child Health, University of Sydney Medical School and Children's Hospital Westmead, Sydney, Australia

10.1136/archdischild-2014-307384.1471

Background Parents and paediatricians in partnership have a unique role in influencing the emotional development of young children. The opportunity presents when parents consult paediatricians about their child's behaviour or developmental problems.

Discussion Infants and young children learn by interacting with and reacting to their environment. Early relationships with their parents foster feelings of trust and security, which influences their relationships with others as they develop and mature.

Paediatricians, through their knowledge of child development, are in a unique position to influence and guide parents in early child-rearing practices. They do newborn examinations and they assess young children through various stages of early development, preschool and school entry. They are often the point of contact in later transition periods such as high school entry and adolescence, particularly when behaviour becomes challenging.

The presentation will touch on theories of development, early experiences, resilience and cultural factors that influence emotional development. It will provide a clinician's perspective on the management of behaviour difficulties and the partnership with parents in order to facilitate optimal emotional development in young children.
Conclusion Paediatricians have an opportunity to influence healthy and positive relationships between parents and their young children that will allow children to develop to the best of their ability and become responsible members of society in the long-term.

\section{PO-0843 EFFECT OF CEREBRAL PALSIED CHILDRENS' SITTING POSTURE ON MOTHERS' QUALITY OF LIFE}

B Aras, O Aras, G Kallem. School of Health Sciences, Department of Physiotherapy, Dumlupinar University, Kütahya, Turkey

\subsection{6/archdischild-2014-307384.1472}

The aim of this study was to investigate the relation between sitting posture of diplegic spastic cerebral palsied children and the quality of life of their mothers. Twenty two children with the diagnosis of diplegic spastic cerebral palsy and their mothers were included in the study. The functional level of children were classified according to the Gross Motor Function Classification System (GMFMCs). Sitting Assessment Scale (SAS) was used to evaluate sitting posture. Nottingham Health Profile (NHP) was used to assess the quality of life of mothers. Spearman correlation analysis was used to investigate the relation between sitting posture of children and quality of life of mothers. The mean age of children and mothers were $6.3 \pm 4.6$ years, $35.7 \pm 8.6$ years, respectively. The median GMFMCs level was 4 . The mean SAS score was $13.2 \pm 3.4$ in children and, mean NHP score was $164.2 \pm 106.7$ in mothers. There was a significant correlation between SAS score and NHP score (rho=-0,622, p < 0.05). Proper sitting posture is important for feeding, carrying and caring of a child. Improvements in sitting posture of children with cerebral palsy may have favourable effects on mothers' and caregivers' quality of life.

\section{PO-0844 ASYMMETRICAL INTRAUTERINE GROWTH RESTRICTION AND LANGUAGE: WHY IS THIS IMPORTANT?}

${ }^{1} \mathrm{Z}$ Kolundzic, ${ }^{2} \mathrm{M}$ Lencek, ${ }^{1} \mathrm{~A}$ Simic Klaric. ${ }^{1}$ Pediatric, County Hospital, Pozega, Croatia; ${ }^{2}$ Pediatric, Faculty of Education and Rehabilitation Sciences, Zagreb, Croatia

\subsection{6/archdischild-2014-307384.1473}

Neurodevelopmental outcome of children born after asymmetrical IUGR is impaired in great amounts of cases. Long term consequences of IUGR deserve special attention, because they could cause poorer cognitive and language abilities, learning difficulties and lower academic level achievement.

There is a small number of data related to language development of children born after IUGR. With regard to the Croatian language there was no research on morphological knowledge for this children, although it is known that linguistic knowledge is important for reading, writing and later school success.

Therefore the goal of this paper is to determine the level of language knowledge, especially morphological knowledge and the correlation between morphological and other linguistic variables in 40 children born after IUGR and their control peers. At the time of examination all 80 children were aged between six and seven years, average cognitive abilities.

Results showed statistically significant differences between children born after IUGR and their control peers on all language tasks, particulary in morphological items: children born after IUGR were significantly poorer. There was significantly higher correlation between morphological abilities and other language 